\title{
INCONFIDÊNCIAS DE ABRIL: IMPACTO DO ISOLAMENTO SOCIAL NA COMUNIDADE TRANS EM TEMPOS DE PANDEMIA DE COVID-19
}

\author{
INCONFIDENCIAS DE ABRIL: \\ IMPACTO DEL AISLAMIENTO SOCIAL EN LA COMUNIDAD \\ TRANS EN TIEMPOS DE LA PANDEMIA COVID-19 \\ APRIL INCONFIDENCES: \\ THE IMPACT OF SOCIAL ISOLATION ON THE BRAZILIAN \\ TRANSGENDER COMMUNITY IN TIMES OF THE COVID-19 PANDEMIC
}

\author{
Manoel Antônio dos Santos ${ }^{1}$, Wanderlei Abadio de Oliveira ${ }^{2}$ \\ e Érika Arantes de Oliveira-Cardoso ${ }^{1}$ \\ ${ }^{1}$ Universidade de São Paulo, Ribeirão Preto/SP, Brasil \\ ${ }^{2}$ Pontifícia Universidade Católica de Campinas, Campinas/SP, Brasil
}

RESUMO: Diante de uma crise sanitária e humanitária sem precedentes, o negacionismo do governo de extremadireita tem conduzido a uma gestão desastrosa da pandemia de Covid-19 no Brasil. Defendemos o argumento de que está em curso um projeto deliberado de extermínio das populações mais vulneráveis. Este estudo tem por objetivo analisar os impactos das medidas de distanciamento social na comunidade trans, buscando oferecer subsídios para articular uma compreensão que favoreça uma gestão ético-política da pandemia. No artigo, desenvolvemos esse argumento em torno das consequências da necropolítica sobre as vidas precárias. Incorporamos as vozes de pessoas trans e ligadas ao ativismo trans que compartilham suas experiências de apoio à comunidade. Situamos os processos sociais em curso que produzem normatizações que regulam e vulnerabilizam os corpos periféricos trans. Solidariedade e medidas para mitigar o sofrimento dos excluídos podem representar uma inflexão no processo em curso de institucionalização da desigualdade.

PALAVRAS-CHAVE: Transexualidade; Covid-19; infecções por coronavírus; pandemias; isolamento social; necropolítica.

RESUMEN: Ante una crisis sanitaria y humanitaria sin precedentes, la negación del gobierno de extrema derecha ha llevado a una gestión desastrosa de la pandemia de Covid-19 en Brasil. Defendemos el argumento de que está en marcha un proyecto deliberado para exterminar a las poblaciones más vulnerables. Este estudio tiene como objetivo analizar los impactos de las medidas de aislamiento social en la comunidad trans, buscando ofrecer subsidios para articular un entendimiento que favorezca un manejo ético-político de la pandemia. En el artículo, desarrollamos este argumento en torno a las consecuencias de la necropolítica en las vidas precarias. Incorporamos las voces de personas trans y vinculadas al activismo trans que comparten sus experiencias de apoyo a la comunidad. Situamos los procesos sociales en curso que producen normas que regulan y hacen vulnerables los cuerpos trans periféricos. La solidaridad y las medidas para mitigar el sufrimiento de los excluidos pueden representar una inflexión en el proceso en curso de institucionalización de la desigualdad.

PALABRAS CLAVE: Transexualidad; Covid-19; Infecciones por coronavirus, Pandemias; Aislamiento social; Necropolítica.

ABSTRACT: In the face of an unprecedented health and humanitarian crisis, the denial of the far-right government has led to a disastrous management of the Covid-19 pandemic in Brazil. We defend the argument that a deliberate project to exterminate the most vulnerable populations is underway. This study aims to analyze the impacts of social distancing measures in the trans community, seeking to offer subsidies to articulate an understanding that favors an ethical-political management of the pandemic. In the article we developed this argument around the consequences of necropolitics on precarious lives. We incorporate the voices of people linked to trans activism who share their experiences supporting the community. We situate the ongoing social processes that produce norms that regulate and make the peripheral trans bodies vulnerable. Solidarity and measures to mitigate the suffering of the excluded may represent an inflexion in the ongoing process of institutionalizing inequality.

KEYWORDS: Transsexuality; Covid-19; Coronavirus Infections; Pandemics; Social isolation; Necropolitics. 


\section{Introdução}

Como desdobramento do golpe político-institucional de 2016, que resultou no impeachment da presidenta Dilma Roussef, o Estado brasileiro está sob controle da extrema-direita, comandada por um líder populista, que se dedica diuturnamente à destruição sistemática das instituições democráticas. Em plena escalada da pandemia da Covid-19, o projeto genocida e eugenista segue em ritmo (a)celerado ${ }^{1}$ e é tão ou mais deletério do que o novo coronavírus, que se alastra nas franjas periféricas das metrópoles, e se adensa com grande desenvoltura e capilaridade pelo interior dos estados brasileiros.

No auge da maior crise sanitária e humanitária do século, assistimos perplexos à postura negacionista das autoridades federais. Antes de termos contato com essa realidade em nosso país, no apogeu da pandemia na Europa, vimos que, na Itália, o aumento exponencial de casos de contaminação pela Covid-19 levou os médicos a escolherem salvar aqueles considerados com "maiores chances de sobreviver" entre os milhares de pacientes que superlotavam os leitos dos hospitais, seguindo inclusive orientação das autoridades do país (Oliveira, Oliveira-Cardoso, Silva, \& Santos, 2020).

No Brasil, desde o início, o presidente adotou uma estratégia temerária de negar a gravidade da pandemia e relativizar a situação, menosprezando a ciência e desdenhando dos mortos: "Alguns vão morrer? Vão morrer. Lamento, é a vida. Não pode parar uma fábrica de automóveis porque tem mortes no trânsito". ${ }^{2}$

Em ambas as situações, percebe-se que se trata de "fazer viver e deixar morrer", definir quem vai sobreviver e quem vai morrer (Butler, 2020), como estratégia e política de controle social implementadas por meio da instrumentalização da morte. Necropolítica, na concepção proposta pelo filósofo camaronês Mbembe (2018), é um conceito que define como governos autocraticamente decidem quem viverá e quem morrerá e de que maneira viverão e morrerão. Na sociedade contemporânea, vastas populações são submetidas a condições de vida que lhes conferem o estatuto de "mortos-vivos" e as relações de poder se materializam pela expressão da morte. É sob esse enquadramento ético-político que devemos dissecar a conduta do presidente e sua fábrica de mortos. ${ }^{3} \mathrm{O}$ cenário caótico sugere que o "projeto" do governo Bolsonaro de gestão ruinosa da pandemia é um esquema ardilosamente programado para instrumentalizar o vírus e colocar seu poder destrutivo e mortífero a serviço da imolação/eliminação sumária dos mais vulneráveis.

Enquanto os números estarrecedores da pandemia decolam e o vírus segue à deriva, desenhando seu rastro mortal, o governo demite o ministro e todo o corpo técnico para militarizar a pasta da Saúde. Em meio à completa desorganização, a evolução da curva de contaminação e morte continuou a acelerar e o alcaide-mor ordena maquiar os números diários de óbitos e novos casos. O menosprezo pela verdade instaura um universo paralelo de esquizofrenia social, com graves consequências para a população mais vulnerável, à custa de vidas cada vez mais precárias. ${ }^{4}$

Outro conceito que lastreia nosso estudo é o de "precarização da vida". Após o atentado de 11 de Setembro de 2001, Butler (2019) elaborou a tese das "vidas precárias", produzidas em resposta às condições de maior vulnerabilidade que se seguiram àquele acontecimento extraordinário. Resguardadas as devidas diferenças, a situação atual de pandemia desencadeada pela propagação do $S A R S-C o V-2$ expõe a tentativa programática do governo brasileiro de negar a cidadania ou, simplesmente, tirar proveito dela para 
eliminar indivíduos considerados abjetos e indesejáveis. O critério que permite diferenciar aqueles que merecem viver e os que devem morrer é permeado por concepções higienistas e eugenistas. Não bastasse a tentativa de domesticação dos corpos trans pela submissão à docilização operada pelo discurso biomédico, na pandemia, notamos o oportunismo do uso político do vírus como instrumento bio-infectante-sistêmico-inflamatório para extermínio sumário de grupos minoritários historicamente desprezados e odiados, como as pessoas que vivenciam as transgeneridades.

Enquanto a pandemia arrasta seu manto mortífero, nos porões e gabinetes necrofílicos do Palácio do Planalto forças antidemocráticas e à margem do ordenamento jurídico conspiram ativamente nos bastidores para instaurar um estado totalitário. Para alcançar seus intentos, neofascistas e suas milícias digitais não se constrangem em tirar proveito de uma tragédia global, propondo ostensivamente que a população desobedeça às recomendações de distanciamento social, expondo assim os mais vulneráveis ao risco de contrair o vírus. Essas ações coordenadas são estratégias sofisticadas, instrumentalizadas por forças necropolíticas que proliferam nas sombras. Tais forças são arregimentadas para extração de gozo de um poder soberano que se alimenta do pacto mefistofélico, cujo triunfo maior é distribuir sentenças de vida e morte. Nos dias de pandemia, isso significa decidir quem terá acesso privilegiado a um leito de terapia intensiva, a um teste para diagnóstico da Covid-19, a Equipamentos de Proteção Individual (EPI), à água encanada para lavar as mãos regularmente. Significa, portanto, ampliar o poder de pontificar sobre a vida e a morte ao sabor de uma ideologia que venera a morte e suas vivandeiras alvoroçadas, excitadas pela nostalgia do autoritarismo.

Enquanto o capitão capitaliza o vírus, exercitando a musculatura de seu estilo antidemocrático de governar, as falanges justiceiras se sentem à vontade para continuar praticando o habitual extermínio seletivo da população periférica. "A polícia vai mirar na cabecinha e... fogo", autorizou o governador do Rio de Janeiro. Provavelmente ele se sente realizado porque, graças à sofisticada bionecroengenharia do vírus coroado, o Estado pode economizar balas. O vírus se encarrega de dizimar os indesejáveis. É só garantir que o Estado se omita e deixe a pandemia grassar à vontade para seguir sua trajetória de transmissibilidade. Aí é só ficar sentado no terraço do palácio assistindo ao triunfo da tanatopolítica e o desenlace de seu espetáculo.

Este estudo parte da premissa de que o impacto da nova realidade criada pela pandemia e pelas medidas de distanciamento social é mais contundente e cruel para as camadas submetidas a processos anteriores de vulnerabilização, como a população trans, considerando o cenário misógino, racista e homotransfóbico contemporâneo. Esse pressuposto está em conformidade com dados preliminares, que já sinalizam que a Covid-19 e as medidas não farmacológicas adotadas para o controle da pandemia são fatores que aprofundam as desigualdades sociais, políticas e de gênero preexistentes. Especificamente no que se refere à população trans no cenário latinoamericano, Panamá, Peru e Colômbia (Bogotá) adotaram políticas de distanciamento físico e social que restringiu a mobilidade dos cidadãos com base em entendimentos binários de gênero: mulheres e homens têm permissão para acessar os serviços essenciais em dias alternados, ignorando pessoas e comunidades que existem fora desse enquadramento hegemônico (Perez-Brumer \& Silva-Santisteban, 2020). Na Índia, onde pessoas trans já são privadas do direito à atenção à saúde devido à sua não conformidade de gênero, com a chegada da Covid-19 elas podem estar em risco aumentado, uma vez que não serão testadas ou cuidadas de forma adequada (Deb, 2020). 
A população LGBTQIA+, ao longo da história, sempre esteve mais exposta à violência, à morte e à violação de direitos (Lira \& Morais, 2020) e, no momento de crise sanitária da Covid-19, as tensões presentes nos corpos dissidentes tendem a ser intensificadas com os efeitos adversos das medidas de distanciamento social (Duarte, 2020). No Brasil, segundo dados da Associação Nacional de Travestis e Transexuais - ANTRA (2020), mesmo durante a situação pandêmica houve aumento no número de casos de assassinatos de pessoas trans em relação ao ano de 2019. Em entrevista à ONU Mulheres Brasil, Bruna Benevides, secretária de Articulação Política da ANTRA, avaliou que, com a pandemia, também tem se observado incremento da vulnerabilidade socioeconômica na população trans: "A maioria são negras, pobres e periféricas, semianalfabetas; muitas não têm sequer cadastro nas organizações governamentais para algum tipo de benefício, como cadastro único, por exemplo; muitas não têm documentação; têm dificuldade de fazer documentação e acessar as políticas públicas de assistência” (ONU Mulheres Brasil, 2020). Ainda mais vulnerabilizadas pela perda de renda, que acentua condições precárias de subsistência, pessoas trans também podem ter dificuldade de dar continuidade ao tratamento transexualizador no Sistema Único de Saúde (SUS), o que gera angústias e sentimentos negativos (Ferreira \& Santos, 2020; Santos et al., 2019).

Desafios contemporâneos, como despatologização das transexualidades, visibilidade trans, combate aos crimes de ódio e questões de necropolítica têm ganhado destaque em fóruns e debates públicos mediados pelas entidades representativas da Psicologia, com lives promovidas pelo Conselho Regional de Psicologia de São Paulo. Os impactos psicossociais do isolamento social têm sido intersecionados com os desafios dos enfrentamentos da transfobia. Nessa dimensão, há que se destacar a produção especificamente desenvolvida por autores/as da população trans durante a pandemia (Conselho Regional de Psicologia São Paulo, 2020; Oliveira, Carvalho, \& Jesus, 2020).

Diante desse cenário sombrio, definimos como questão norteadora de nosso estudo: Como as pessoas trans estão vivenciando a quarentena/isolamento social? Este estudo teve por objetivo analisar os impactos da situação de emergência sanitária e das medidas de distanciamento social na comunidade trans, buscando oferecer subsídios para articular uma possível gestão ético-política da pandemia.

\section{Método}

Trata-se de uma pesquisa de abordagem qualitativa, amparada na perspectiva construcionista social para análise da produção de sentidos do cotidiano (Spink \& Medrado, 2000). O processo de produção de sentidos é analisado segundo as práticas discursivas do cotidiano, definidas como práticas sociais que envolvem pessoas engajadas em constantes jogos de trocas simbólicas em um espaço de interpessoalidade que também é socialmente construído.

Acompanhando o avanço vertiginoso do novo coronavírus pelo interior do país, realizamos um estudo com pessoas trans e ativistas de organizações LGBTQIA+ que compõem a rede de apoio à população trans. Consideramos que o ponto de vista de quem está duplamente descentrado - em termos de identidade de gênero e de viver distante da metrópole - pode aportar visões diferenciadas e inexploradas sobre o universo trans.

Buscamos explorar "se" e "como" as tensões vividas na fase inicial da pandemia se desdobram e se exacerbam em um cenário de permanente disputa de narrativas, 
aparelhamento ideológico do Estado, ações e inações alienantes dos gestores públicos, com destaque para a preocupante instrumentalização da pasta da saúde no governo Bolsonaro por militares sem qualquer formação em saúde pública.

Participaram do estudo cinco colaboradores/as, que tinham entre 25 e 38 anos, pelo menos 10 anos de escolaridade, baixa qualificação profissional e pertenciam ao segmento socioeconômico baixo ou médio da população. Antes da pandemia, exerciam ocupações no ramo de segurança, vendas, salão de beleza, magistério e telemarketing.

O corpus de pesquisa foi constituído pelo método de "bola de neve”. As entrevistas foram realizadas individualmente e por via remota no período de contenção comunitária, em respeito às regras do distanciamento social e de acordo com a disponibilidade de cada participante. A conversação foi mediada por uma questão norteadora: "Conte-me como está sua vida desde que foi adotado o isolamento doméstico como medida de contenção da pandemia."

As entrevistas tiveram duração média de 30 minutos e foram audiogravadas e, posteriormente, transcritas na íntegra, constituindo o corpus da pesquisa. Foram realizadas leituras exaustivas das entrevistas para delimitação dos eixos temáticos. Os resultados foram analisados considerando o contexto sócio-político do país e da gestão governamental da crise sanitária, tendo em vista que os sentidos sobre os impactos da pandemia são produzidos na trama social em que as vidas e os corpos trans acontecem. O projeto de pesquisa seguiu os princípios éticos da Resolução 466/2012 do Conselho Nacional de Saúde.

\section{Resultados e discussão}

Seguindo os passos sistemáticos de análise, os pesquisadores buscaram dar visibilidade à produção de sentidos. Foram construídos três eixos temáticos.

\section{Nossos corpos descartáveis, ou: porque cada vida importa}

"As pessoas trans eram invisibilizadas e continuam sendo esquecidas durante a pandemia" (participante). A disseminação vertiginosa do novo coronavírus forjou um cenário de conflagração e comoção global sem precedentes desde a segunda guerra mundial. A pandemia fomenta um espaço-tempo de exceção, que tende a aprofundar as contradições e desigualdades sociais e de gênero preexistentes, acirrando a transfobia e a violação sistemática de direitos das pessoas trans (Balzer \& Hutta, 2012), incluindo o direito à saúde.

São vidas que jamais poderiam ter sido negligenciadas. Segundo a OMS, em tempos de pandemia, é papel dos governos oferecer proteção social às populações vulneráveis, como povos indígenas, pessoas que vivem em situação de rua e moradores de comunidades pobres. Essas "vidas precárias", mais do que nunca, necessitam receber apoio e cuidados em saúde. A "negligência” governamental deve ser lida como violência, que não pode ser atribuída apenas à inépcia da gestão e ao total despreparo do ocupante do cargo de presidência da República. Para além disso, é projeto ativo, estrutural e programático de um Estado que prioriza e protege certas vidas em detrimento de outras (Butler, 2020). "As trans que estão no trabalho sexual estão literalmente desesperadas, porque não conseguem ganhar seu sustento. Nunca se falou, nos espaços públicos, na necessidade de fazer política pública para essas pessoas" (participante). 
Corpos trans causam ao mesmo tempo estranhamento e fascíno, e é esse efeito perturbador que as autoridades tentam suprimir e manter longe da vista do público. Butler (2020) examina as formas de violência não-física, sobretudo a negligência e a discriminação, a partir da resposta infame do governo Trump aos efeitos da pandemia entre comunidades de baixa renda. No Brasil, que vive a calamidade pública dos primeiros meses da pandemia, o arremedo do presidente estadunidense segue a liturgia macabra de seu projeto genocida, disparando declarações matinais que minimizam a gravidade da situação e vilipendia a memória dos mortos por Covid-19. Enquanto isso, o vírus segue sua escalada sem encontrar barreiras, simplesmente porque nenhuma estratégia ou plano de ação central foi traçado visando à contenção do avanço da transmissão. A curva epidemiológica acelera de forma exponencial e em pouco tempo o país se torna o epicentro da doença na América Latina. ${ }^{5}$

Um participante conta que um homem trans de 21 anos, que estava transicionando, teve de suspender o uso de hormônios e parar de se consultar com seu endocrinologista porque ficou sem emprego e amargou uma redução drástica de sua renda mensal com a pandemia. Ferreira e Santos (2020) repercutem o depoimento de um homem trans de 23 anos, recém-chegado à capital paulista, que não conseguiu se cadastrar em um serviço que possibilitaria que ele mantivesse o tratamento hormonal em seu novo domicílio. "Minha prioridade nessa pandemia é manter o meu hormônio." Reedita-se, assim, um problema já conhecido: o distanciamento entre o sistema de saúde e os corpos trans. Ouvindo as preocupações de outros homens e mulheres trans, as autoras concluíram que o receio dos efeitos da suspensão do tratamento hormonal se soma ao medo de serem contaminados/as pelo novo coronavírus.

A necropolítica do governo Bolsonaro é máquina de matar bem azeitada, que politizou o vírus para instrumentalizar sua pontaria mortífera contra populações vulneráveis que interessa ao sistema descartar. Segundo Caravaca-Moreira e Padilha (2018, p. 1), a "necropolítica trans é uma prática tecnológica ininterrupta de violência estrutural e institucional contra o dispositivo da transexualidade, que considera a morte não como um fenômeno meramente biológico, mas moral, social e político”.

Uma mulher trans me pediu para ajudar ela a fazer o cadastro do auxílio emergencial do governo. Ela não tinha acesso à internet, nem sabia como fazer o pedido. E quando veio a resposta, deu que a renda dela era acima do limite. Ela não consegue receber, não se encaixa em nenhuma categoria do governo de quem pode receber o auxílio. (Participante)

As várias facetas da exclusão se intersecionam. Exclusão social. Exclusão econômica. Exclusão digital. Uma participante lembra da Campanha \#FiqueEmCasa, "mas quem, nesse país, pode se dar ao luxo de manter o isolamento social sem correr o risco de perder o emprego?" Outro depoimento propõe que está sendo encenado um jogo perverso, no qual os mais vulneráveis estão sendo empurrados para o abismo das ruas, como se fossem "boiada indo para o abatedouro": "Uma quarentena que está se prolongando e as pessoas pobres não têm como sobreviver. Aí voltam para as ruas, pegam ônibus lotados, se aglomeram em filas de banco, onde vão se infectar e transmitir o vírus para outras pessoas". A OMS recomenda que as pessoas evitem permanecer em ambientes lotados e mal ventilados, "mas muitas pessoas trans vivem em condições precárias de moradia". Inquérito epidemiológico sobre o avanço do novo coronavírus, conduzido pela Secretaria Estadual da Saúde do Espírito Santo, evidenciou que se infectaram mais aqueles que usam transporte público para irem ao trabalho. Reses inocentes a caminho da morte? 
A pandemia tem implicado em lógicas e efeitos problemáticos de segregação espacial, como a tecnologia biopolítica de gestão do corpo social (Sexuality Policy Watch [SPW ], 2020). "Quem consegue manter a rotina do confinamento é a pessoa que tem a comodidade de uma vida confortável e sem complicações” (Participante). Quem luta diariamente pela sobrevivência está em situação de vulnerabilidade. Sabemos que fome, falta de renda e desinformação prejudicam as políticas de combate ao vírus. Em nosso estudo encontramos que a insegurança alimentar é a preocupação imediata, mas não a única. Um participante expôs de forma crua, mas transparente, o dilema que tem vulnerabilizado as pessoas trans que trabalham como profissionais do sexo: "Ou vai morrer de fome, ser despejada, ter a luz cortada, ou vai para a calçada em busca de seu sustento”. As vulnerabilidades são cruzadas e ampliadas (Outright Action International, 2020). Pessoas da comunidade LGBTQIA+ que vivem com HIV/Aids estão com dificuldades de se alimentar adequadamente, o que é uma condição básica para que mantenham seu sistema imunológico funcionando bem. Há quem dependa da doação de cestas básicas por organizações LGBTQIA+ para poder se alimentar e conseguir tomar seus remédios regularmente. "Quem tem fome tem pressa". Também há quem precise se deslocar para outro município para fazer seu acompanhamento e seus exames com regularidade, e que com a restrição da mobilidade, imposta pelo isolamento, estão encontrando dificuldades, adiando consultas e colocando em risco a manutenção de seu tratamento.

Para Butler (2020), a questão é: quem conta como uma vida que importa e quais são as vidas consideradas dispensáveis, substituíveis? Há uma métrica tácita que avalia qual é a vida valiosa e qual não vale nada. "Parece que estamos vivendo um momento assim: quem não aguentar, vai morrer. E quem aguentar vai continuar trabalhando e fazendo a roda da economia girar" (participante). Uma das táticas retóricas do (des)governo Bolsonaro foi contrapor economia e saúde. Os mais pobres, habituados a viverem em condição de desamparo crônico, agora se veem espremidos entre as taxas de mortalidade e de produtividade. ${ }^{6}$ A vulnerabilidade diferenciada é um traço biopolítico da pandemia.

Situamos o corpo como objeto privilegiado para a comunicação de processos socioculturais e focalizamos sua incidência sobre o corpo periférico. A noção de corpo periférico engloba a corporalidade da qual emanam signos desvalorizados pelos padrões constituintes da centralidade corpórea: deformidades físicas, o corpo com amputações, o corpo gordo (Fernandes \& Barbosa, 2016). E há o corpo que carrega um vírus. Um corpo-vetor. Muitos corpos LGBTQIA + vivem com HIV/Aids e, com a chegada do novo coronavírus, a comunidade passou a vivenciar uma pandemia dentro de outra pandemia. O corpo que abriga o HIV constitui-se como fonte de estigma e locus de sofrimento psicológico nos processos interacionais, e esse percurso de estigmatização está se repetindo com o SARS$\mathrm{CoV}-2$, na medida em que ele é deslocado para a periferia e atinge os corpos mais vulnerabilizados e menos capazes de oferecer resistência.

A interrogação que se pode estabelecer é: como está sendo construído o corpo periférico como vetor de transmissão do vírus para outros corpos que, com ele, vivem amontoados em barracos, casebres e palafitas, locais com alta densidade populacional, muitas vezes com condições precárias de higiene, sem ventilação adequada ou acesso a condições de saneamento básico? Que impactos essa assunção particular do corpo pode ter nas vivências psicológicas e na vida social (Fernandes \& Barbosa, 2016) daqueles que são lidos como corpos-periféricos-contagiosos-fragilizados, que não têm condições objetivas de praticar o distanciamento social, tornando-se assim mais expostos à infecção? 
Para quem tem condições materiais de se manter confinado em sua casa espaçosa e arejada, as preocupações geralmente se concentram em torno da invisibilidade, periculosidade e imprevisibilidade do patógeno. De fato, para quem pertence à classe média/alta, o sentimento de ameaça é constante, assim como o temor da perda do controle sobre o planejamento da própria vida; o inimigo oculto e temido pode estar à espreita em toda parte, até que possa encontrar uma brecha para romper barreiras e invadir o refúgio supostamente seguro do lar. Já para os mais pobres e vulneráveis, em especial algumas pessoas trans que estão acostumadas a defender o seu pão de cada dia batalhando pela sobrevivência nas "quebradas" da vida, o regime de urgência da vida e a necessidade de sobreviver e chegar viva após mais uma noite incerta fazem com que elas não tenham tempo para temer a morte. Elas estão ocupadas em se defender da fome, da violência policial, dos grupos de extermínio, das infecções sexualmente transmissíveis, dos suprematistas skinheads, do fanatismo religioso que as elegem como bode expiatório e alvo preferencial dos discursos de ódio. Aliás, a pandemia também tem desnudado a situação de mulheres que ficaram mais expostas a episódios de violência doméstica e familiar, e que se deparam com a total ausência de políticas de acolhimento institucional, apoio e proteção integral para si e seus filhos.

\section{Da doença sem metáfora à barbárie sem máscara}

Na sociedade do hiperindividualismo contemporâneo, a construção social dos corpos periféricos (Fernandes \& Barbosa, 2016) atende ao ideal neoliberal. Em tempos de pandemia, a pressão da classe dominante pela reabertura precoce da economia levou alguns formuladores de políticas públicas a recorrerem à velha tese de "imunidade de rebanho", que presume que aqueles que são fortes o suficiente para suportarem o vírus desenvolverão imunidade e sobreviverão. Assim, com o decorrer do tempo, formarão um exército imune e capaz de trabalhar (Butler, 2020). Essa ideia combina com o pressuposto do darwinismo social, o qual sustenta que as sociedades que tendem a evoluir são aquelas nas quais os mais aptos sobrevivem e os menos capacitados sucumbem, o que é visto pelos cínicos da ultradireita como auspicioso porque os mais "fracos" não irão passar seus genes adiante, cessando assim sua desditosa linhagem. No mundo em convulsão no qual vivemos, em plena era do neoliberalismo exterminador de futuros, as minorias vulneráveis são as destinadas a não sobreviverem. Delas se espera que cumpram resignadamente sua sina. Sina de rebanho? Rebanho da imunidade? Nas palavras da participante: "gado a caminho do matadouro".

Assim, não apenas esse segmento social, como também populações inteiras são "deixadas para morrer”, evocando uma expressão de Foucault recuperada por Butler (2020) em sua reflexão sobre a pandemia provocada pelo novo coronavírus. São trabalhadores/as que vivem amontoados/as em espaços habitacionais exíguos, privados/as de assistência em saúde e que, sob as circunstâncias atuais, logo estarão disputando um leito de UTI na rede pública, sufocados/as e expostos/as à morte com intenso sofrimento respiratório. Esse é o retrato sem retoque do darwinismo social brasileiro, a realidade contundente “que não sai na imprensa”. O flautista de Hamelin pode levar o rebanho ao matadouro.

A vida no mundo confinado de 2020 pode ser novidade para a maior parte da população, menos para o segmento trans, para quem o isolamento doméstico não é propriamente uma nova realidade criada pela pandemia. A restrição de mobilidade está relacionada ao medo de colocar a cara na rua. "A gente já vivia isolada antes da pandemia" (Participante). "É uma população que, historicamente, já vive na carne o distanciamento social. 
A maioria dos LGBTs não moram com suas famílias. As trans eram e continuam invisibilizadas e agora estão sem trabalho, sem renda” (Participante). São pessoas que não contam com o apoio familiar em sua rede de suporte social e que desde muito cedo tiveram que se tornar independentes e subsidiar seus próprios meios de sobrevivência (Soares, Feijó, Valério, Siquieri, \& Pinto, 2011). Com a pandemia, repentinamente se viram privadas de suas condições de subsistência. A discriminação violenta e abusiva a que estão sujeitas em suas famílias contribuem para que as pessoas trans se tornem mais dependentes das redes de apoio social e, por essa razão, elas podem ter experiências negativas com o isolamento social, acentuando os sentimentos de solidão e desamparo desencadeados pela omissão do poder público (Sexuality Policy Watch [SPW], 2020).

A implementação das medidas de controle da disseminação da infecção impôs uma guinada na vida dessas pessoas já vulnerabilizadas justamente em um momento de notório retrocesso nas políticas de proteção social desenhadas para a população LGBTQIA+, acompanhando o desmonte dos programas e políticas de ações governamentais de enfrentamento da pobreza e qualificação profissional. "Tem os que saíram da escola e não voltaram a estudar e, para arrumar emprego enquanto pessoa trans já é difícil, é muito difícil. Você não tem uma capacitação profissional, não tem um curso" (participante). Nota-se, assim, que o distanciamento social se configura como processo político a que se associam as experiências de opressão e violência perpetradas pela necropolítica trans, configurando um espaço de negociação cujos sentidos de resistência se tensionam no cotidiano das pessoas.

Em 2019, o Congresso Nacional, em grande parte entregue à sanha do canibalismo necrocapitalista, retirou direitos trabalhistas e glosou a previdência dos trabalhadores. Em 2020, no contexto pandêmico, foram observadas barreiras que impediram as pessoas trans de terem acesso até mesmo ao programa emergencial de auxílio financeiro, criado como mecanismo de garantia mínima de sobrevivência das camadas populares afetadas pela paralisação da atividade econômica. Pessoas trans também sonharam com os $\mathrm{R}$ \$ 600,00 que, ao menos temporariamente, as tirariam da extrema pobreza. Sem sucesso. Para os corpos abjetos não há sequer o consolo das migalhas que caem da mesa do banquete dos poderosos. "Fiquei com o coração apertado vendo que ela não conseguia acessar o aplicativo da Caixa".

Corpos famélicos são presas fáceis do vírus; desprotegidos, "nus", precarizados, necessitam se deslocar, arriscando-se nos espaços de intensa circulação e aglomeração de pessoas por onde o novo coronavírus está circulando com desenvoltura. O capital, ávido e amoral, entrega ao banquete da morte o que resta dos corpos e vidas precárias. A necropolítica do governo não tem pudor em atirar os(as) vulneráveis na fogueira. Invisíveis, desprezados, vitimados por campanhas de ódio, seus corpos estão fadados a engrossar as estatísticas dos mortos atualizadas diariamente, induzindo à normalização do inaceitável em meio a tantos lutos não autorizados.

A população trans, que sempre esteve excluída do já precário sistema de proteção social, nem mesmo consegue ser alcançada pelo programa do auxílio emergencial desenhado para amortecer o desespero dos despossuídos. Para quem busca meios que lhe permitam sobreviver há urgência. A dor é aqui e se chama descaso com os mais fragilizados, levando ao desamparo e à desesperança. "Essa solidão sempre existiu. Para eles, somos a escória. Sempre tivemos nossos direitos violados. Sempre tivemos a morte no nosso calcanhar".

No espaço público, onde cada vez mais se exacerbam as disputas pelo direito ao pertencimento territorial, a população trans é exposta a experiências estigmatizantes (abusos verbais e físicos, humilhação social, dificuldade em encontrar um emprego) 
e é sistematicamente banida do convívio social e das ruas, assim como sofrem rejeição na escola, na igreja, no local de trabalho e do sistema de saúde. Os processos aniquiladores maciços das subjetividades trans fazem com que essas pessoas muitas vezes se sintam emparedadas. “O que a pandemia está fazendo com a cabeça da gente? Tudo o que era, agora já não é mais e você tem que se adaptar a essa nova realidade sem ter nenhum preparo ou amparo do poder público. Assim fica difícil sobreviver" (participante).

Em plena pandemia, a população brasileira tem sido obrigada a acompanhar shows diários de incivilidade. É o que se viu em uma situação particularmente intolerável e nauseante, quando o país assistiu, estupefato, ao vídeo da reunião ministerial de 22 de abril de 2020 que, posteriormente, teve sua divulgação liberada pelo Supremo Tribunal Federal para conhecimento público. Foi um espetáculo grotesco que expôs as vísceras de um governo de bajuladores e oportunistas. A pantomima bizarra, encenado para os comensais abastados, foi recheada com 33 palavrões, exortações às armas e à ditadura ("É escancarar a questão do armamento aqui, quero todo mundo armado, povo armado jamais será escravizado", esbravejou o presidente, apoplético). No coração do poder caíram de uma só vez todas as máscaras do esquadrão ministerial, e o espetáculo burlesco da necropolítica mostrou sua face nefasta sem disfarce, na forma de uma tecnologia ininterrupta de violência sistêmica, estrutural e institucional direcionada contra os vulneráveis - que, evidentemente, não foram convidados para o grande banquete na Corte. Na grande mesa colonial uma maioria de homens cis brancos, supostamente heterossexuais, tiveram acento e voz, liderados pelo ex-capitão escoltado por dois generais.

Em um país no qual a violência é problema endêmico, a apologia ao armamento da população e a defesa da desregulamentação do controle do Estado sobre a circulação de armas de fogo promovem o acirramento da letalidade contra a população pobre, alimenta os conflitos armados no campo e estimula o massacre dos povos indígenas. Ainda em relação à fatídica reunião ministerial de 22 de abril, vale lembrar que ela aconteceu um dia depois da data em que se comemora o dia da Inconfidência Mineira, que se deu na próspera Vila Rica, capital da província das Minas Gerais. Nesses tempos em que "ser mascarado” virou virtude, caem definitivamente as máscaras da hipocrisia.

Na reunião do ministério das trevas do governo Bolsonaro, o ministro da Economia reafirmou o ideário ultraliberal pelo Estado mínimo e declarou que o combate à desigualdade "é bom apenas para o discurso". ${ }^{7}$ Sem qualquer menção ao SUS, sem sequer esboçar um plano coordenado de ação multissetorial para combate à pandemia, esse teatro do absurdo oferece um prenúncio de que a exacerbação da desigualdade será o saldo amargo da Covid-19, além da centena de milhares de vidas interrompidas. Os bastidores do poder revelam que os pobres mais uma vez serão constrangidos a pagar a conta. Sob tutela militar e a batuta do presidente, o recém-empossado novo ministro da saúde, em transe, assistiu à ampliação da crise, ao desmonte da estrutura da pasta e se esquivou de liderar o combate à pandemia. Dias depois cairia o segundo, em menos de dois meses em plena pandemia. ${ }^{8}$

\section{Somos forjadas/os na resistência: existências-dissidências}

Para quem está calejado/a de viver as aflições das margens, a verdade é sempre contundente e frontal. "Precisamos escancarar a verdade. Somos nossos corpos sobreviventes de um projeto de extermínio" (participante). Na medida em que o sujeito é expropriado do controle de sua vida e que lhe é imposta uma vida "nua", resta-lhe estreita 
margem na qual lhe é permitido se inscrever socialmente em "uma macroeconomia geral do terror, que torna visível o potencial (im)produtivo e destrutivo do necropoder trans" (Caravaca-Moreira \& Padilha, 2018, p. 9).

Muitas pessoas trans se viram forçadas a voltar para a casa dos pais. O que significa, para a população trans, estar de "volta ao lar" onde são abominadas e de onde tantas vezes foram escorraçadas? O lar, para as pessoas trans, não é esse lugar aprazível reproduzido nos manuais de Psicologia, que ignoram as condições materiais que constituem as existências-dissidências, mas sim reedição penosa de exercícios de submissão ou resistência. No entanto, o conhecimento produzido sobre família pela Psicologia em larga medida pressupõe o reduto familiar como lugar onde se é estimado e apoiado, refúgio narcísico, porto seguro para expressão dos sentimentos (Lasch, 1991). Na privacidade das famílias de origem das pessoas trans esses sentimentos são preponderantemente hostis e muitas vezes em nome deles se cometem atrocidades, que permanecem encobertas pelo pacto de silêncio e pela vergonha que despertam quando expostas.

Pessoas trans carregam histórias de rejeição familiar. Na pandemia, o confinamento forja um convívio intenso, uma reaproximação às relações tóxicas, que podem agravar as manifestações de violência ("Um pai passa o dia chamando o filho de veadinho porque não suporta as músicas que ele gosta de ouvir”). O espaço da intimidade pode se converter em um campo de batalha violento e sangrento. A invisibilidade da violência doméstica e familiar é uma das formas de manifestação do poder patriarcal, exercido nesse cenário estruturado em torno de práticas opressoras. Daí a importância de trabalhar com a família: "antes a gente já oferecia o amparo de ir e conversar com os pais da pessoa trans, e depois os pais começam a mudar, começam a aceitar aquilo de uma forma melhor, sem ter violência ou agressão dentro de casa, seja verbal ou física (Participante).

A fragilização das relações familiares mostra que a família pode não ser um território de pertencimento e manifestação de afetos positivos como deseja a vã Psicologia (Lasch, 1991), mesmo em um cenário de conflagração pandêmica. Isso nos convida a aprender a (des)aprender, não simplesmente readequar ou remodelar velhos conceitos e reler o farto conhecimento já produzido sobre a inserção da instituição familiar no processo de reprodução do cotidiano da vida social. A pandemia está aí a nos sinalizar, ao vivo, em cores e à queima-roupa, que precisamos de uma descolonização dos saberes e práticas, com ações emancipatórias em face das diferentes formas de dominação. Cabe-nos, então, questionar: que respostas podemos dar frente à erosão dos parâmetros mínimos de civilidade? Quais os desafios a serem superados, na perspectiva da garantia dos direitos das pessoas trans, e o que pode contribuir para fortalecer a luta contra os mecanismos de saneamento das dissidências sexuais e de gênero? Como neutralizar o projeto sórdido de governo que tentou tirar proveito da pandemia para instituir um regime autoritário, com as $\mathrm{so}(\mathrm{m})$ bras da ditadura?

"Quem pode acabar com essa pandemia, que diariamente nos assassina?" Assim sintetizou o psicólogo Daniel Coelho Silva Brandão, homem trans, em live promovida pelo Conselho Regional de Psicologia São Paulo (2020a), ao divulgar um poema-tributo que ele dedicou à memória do dançarino carioca Demétrio Campos, homem trans que foi "suicidado".

Teorias não são verdades absolutas, mas apenas maneiras provisórias de ler, organizar e produzir conhecimento e orientar uma práxis legitimada por uma comunidade científica particular em dado contex to social e histórico. Produzir novas articulações teóricas a partir da produção de sentidos captados nas populações vulneráveis frente à politização da pandemia pode ser uma estratégia de resistência, especialmente em um momento 
histórico de desmonte dos sistemas de proteção social e de retirada de direitos conquistados pela luta dos trabalhadores, quando se nota o sucateamento dos equipamentos de proteção das pessoas e famílias mais vulneráveis.

\section{Considerações finais}

Este estudo examinou os impactos significativos e persistentes da disseminação do novo coronavírus sobre a população trans. As análises dos sentidos produzidos nesse contexto permitiram iluminar algumas dinâmicas vivenciadas sob a pandemia. Frente às questões emergenciais evidenciadas, qual deve ser o papel da Psicologia em períodos de crise pandêmica? Diante da completa ausência de ações governamentais, que estratégia de intervenção psicossocial se vislumbra como útil e exequível em tempos tão conturbados, para reduzir as iniquidades e mitigar os impactos que incidem sobre os corpos trans? Já se sabe que a pandemia está acentuando as assimetrias nas relações hierárquicas de desigualdade social e de gênero, agudizando as disparidades históricas e aprofundando iniquidades preexistentes.

O silêncio que paira na sociedade brasileira a respeito das consequências devastadoras da pandemia sobre a vida das pessoas trans evidencia sua persistente invisibilidade social. Mostra, também, a face perversa da indiferença crônica das camadas sociais médias e alta em relação às condições de vida dos segmentos populacionais marginalizados. $\mathrm{O}$ vírus foi recondicionado e convertido em poderoso instrumento de dominação, opressão e exploração necropolítica.

Qual a margem de liberdade que temos, quando sabemos que a restrição de mobilidade e circulação pelos espaços compartilhados continuará sendo uma tônica até que uma vacina seja disponibilizada (e até mesmo depois)? Sabemos que o distanciamento é apenas físico e não social (distanciamento não deve ser confundido com isolamento social), mas ele adquire uma conotação particular nas pessoas trans devido ao seu baixo nível de proteção social e ao projeto de aniquilamento em curso. Isso aumenta a responsabilidade da Psicologia no que tange à sua contribuição para a tarefa coletiva de produzir uma análise psicológica dos grupos afetados pelo distanciamento social decorrente da Covid-19.

É preciso ampliar o âmbito de ação na perspectiva do trabalho em rede com os programas de proteção e atenção à população trans, para mitigar os danos biopsicossocias associados ao distanciamento social. São tessituras lentas de processos biopolíticos, necessárias para que as pessoas trans possam se sentir legitimadas em suas experiências, sentidos e identidades. Se a pós-modernidade nos ofereceu a pluralidade e o questionamento das certezas e convenções como marcas de uma época em vertigem, precisamos pensar que enlaces são possíveis, na intersecção com outras pautas progressistas e de agendas dissidentes. Nessa direção, a aliança de corpos é fundamental, assim como lutar contra a patologização do corpo trans (Bento, 2004), o que implica romper com uma herança há muito sedimentada nas representações e sentidos cristalizados acerca das transgeneridades.

As medidas de isolamento social também têm produzido violência, assim como outros riscos e abusos contra as pessoas nas quais o sistema sexo-gênero não está em conformidade com o padrão cis-heteronormativo, com aumento dramático da violência letal e do número de suicídios entre pessoas jovens trans e outros/as LGBTQIA+. No entanto, essas hostilidades até hoje não alcançaram a mesma visibilidade legitimamente conferida à violência contra a mulher e o feminicídio (Sexuality Policy Watch [SPW], 2020). 
Mais uma vez, estamos diante da "realidade que não sai na imprensa”. Essa omissão programática reforça o menosprezo da mídia especializada pelos corpos que portam desejos e sexualidades dissidentes. A violência também se faz presente na invisibilização das configurações familiares e conjugalidades trans (Alexandre \& Santos, 2019; Baptista-Silva, Hamann, \& Pizzinato, 2017). É preciso responder com nossos conhecimentos, ativismos e subversões do normativo, organizando a insurgência pacífica e obstinada dos despossuídos, como propõe Butler (2020) com a perspectiva de valorizar a força transgressora da não violência.

Consideramos que esse é um passo importante para positivar o corpo trans como acontecimento político (Costa-Val \& Guerra, 2019). Mas, na "crônica de várias mortes anunciadas", como dar visibilidade aos fenômenos relacionados com a violência estrutural, sistemática e institucional nas sociedades latino-americanas que estigmatizam e mortificam a população trans? (Caravaca-Moreira \& Padilha, 2018). Como viabilizar novos agenciamentos de corpos e desejos dissidentes-persistentes-resistentes-insurgentes às novas/velhas formas de opressão? Uma posição potente nos convida a "pensar em formas de alianças entre os corpos que não passem exatamente por uma identidade específica, mas por algo que permita um tipo de agrupamento não totalitário capaz de abarcar as singularidades" (Costa-Val \& Guerra, 2019, p. 132). O corpo trans incomoda, perturba e causa estranhamento ao deslocar os gêneros da lógica cis-heteronormativa que sustenta o dispositivo da sexualidade segundo a lógica binária, acenando para outras possibilidades de expressão e formas de existência (Alexandre \& Santos, 2019).

Que "vacina" temos para mitigar os efeitos da relação entre as políticas sociais cis-heteronormativas e o regime de invisibilização e morte física e simbólica das pessoas trans na cultura latino-americana? Que respostas podemos e devemos - ética e politicamente articular face à questão posta por um dos participantes a respeito do trabalho de militância: "É a gente tentando educar essas pessoas para que o sofrimento nosso seja um sofrimento menor, porque nossa vida é um sofrimento diário e muitas vezes as pessoas não entendem, vêm com pedras e paus na mão, armadas de unhas e dentes. Nossos direitos são negados."

$\mathrm{O}$ ativismo, em meio aos desafios do combate à Covid-19, aparece nas falas dos/as participantes como uma confluência de esforços para proteger a vida dos que lutam por uma vida justa e partilhada, enquanto a democracra era atingida e vilipendiada pelo maior mandatário da República em suas inconfidências de abril. Nesse cenário, como robustecer uma gestão ético-política das consequências da pandemia nas populações pobres, na comunidade trans, negra, periférica? Para os neofascistas, o caos é o melhor cenário, inclusive para justificar o extermínio dos "matáveis".

À solidão e isolamento do tirano de plantão, devemos contrapor o fortalecimento dos laços solidários entre os diferentes coletivos e ativismos. Devemos valorizar os projetos insurgentes e decoloniais dos coletivos de cultura e comunicação das periferias das cidades. E, pensando em formas de alianças entre os corpos, devemos apostar no acirramento de tensões latentes da sociedade, contestando as respostas estatais como mostra a onda de protestos populares antirracistas e contra o genocídio da população negra que varreu os Estados Unidos em junho de 2020, deflagrada pela morte de George Floyd, dando um novo significado para o movimento "Vidas Negras Importam".

A pandemia ceifou milhares de vidas precarizadas e tirou muito mais empregos dos pobres e vulneráveis, aprofundando o fosso - que agora ficou mais visível e abissal, inclusive nos países ricos. Se já faltavam empregos e soluções para os excluídos antes da catástrofe, o que podemos esperar para o período posterior à turbulência sanitária? 
O novo coronavírus (ou seus sucedâneos) continuará no encalço dos mais vulnerabilizados, e os percalços vividos até o momento têm mostrado que é preciso repensar o papel do Estado, desmascarar a ideologia que está sendo construída em torno do "novo normal" e desvendar os olhos para que se enxergue a cooptação da morte como empreendimento político direcionado à dizimação da população de travestis e transexuais. Para alguns, a solidariedade e as medidas para auxiliar os excluídos poderiam representar uma inversão no processo de institucionalização da desigualdade sistêmica. Mobilizações/ações solidárias e doações inéditas marcam a mobilização de combate à Covid-19. O desafio, contudo, é institucionalizar as ações contra a desigualdade ao final da crise. Um labirinto por enquanto inextricável.

A pandemia marca uma inflexão. Fim de uma era? Estaria o neoliberalismo sitiado? Ainda é muito cedo para qualquer vaticínio. A gestão caótica pelo governo Bolsonaro já está sendo julgada pela população. Certamente será condenada pela história. Esperamos que isso aconteça antes que um preço terrível tenha sido pago em vidas humanas. Vidas que importam porque cada vida importa. Se morrer é "inevitável”, como afirma o Presidente, viver é inegociável.

\section{Notas}

1 Diz-se "celerado" aquele que cometeu ou é capaz de cometer crimes de morte ou violência, portanto, um facínora, criminoso.

2 Em pronunciamento à nação em 24 de março de 2020, na fase inicial da pandemia, o presidente da República, contrariando orientações da Organização Mundial da Saúde (OMS), criticou o "confinamento em massa" e pontificou que não via motivos para que prefeitos e governadores tenham interrompido as aulas, porque crianças, segundo ele, não morrem de coronavírus. Atentar contra a vida de crianças, além de ato criminoso, é exercício de necropolítica. O ministro da Economia declarou: "Não sou médico, mas os mais velhos devem ficar em casa; os mais jovens, com mais saúde, devem circular, ir trabalhar [...] Se ficar todo mundo em casa, a economia entra em colapso." Isso também é exercício de necropolítica. Nessa ocasião, uma assessora do ministro chegou a declarar, segundo os órgãos de imprensa, de que via a perspectiva de morte de milhares de idosos como positiva para o país reduzir o déficit previdenciário.

3 A necropolitização do vírus se evidencia nessa breve e triste cronologia. Início da pandemia: "Coronavírus é invenção da imprensa". Primeira morte: "É só uma gripezinha". 10 mortes: "Tenho histórico de atleta". 100 mortes: "Vão morrer alguns idosos". 1000 mortes: "Não sou coveiro". 10.000 mortos: "E daí?" 20.000 mortos: "A culpa é dos governadores e prefeitos". 35 mil mortos: "Bolsonaro esconde número de mortes e total de casos por coronavírus no Brasil”, conforme manchete do The Guardian. 
Em 26 de março de 2020, o presidente declarou: "O brasileiro tem que ser estudado, ele não pega nada” (2020, março, 27). Em entrevista concedida à TV Band, mais uma vez defendeu que as pessoas voltem a trabalhar: "Quem tem emprego, vai trabalhar, não pode se esconder. Não podemos agir desse modo irresponsável. O vírus, mais forte ou mais fraco, vem. Que nem chuva, vai se molhar. Não pode se esconder, se enclausurar, ficar de quarentena, e tudo bem. Não é tudo bem, não. [...] Vamos quebrar o Brasil por causa do vírus? E outra coisa: o desemprego tem relação direta com a violência”. O capitão desacreditou os números divulgados pelo próprio Ministério da Saúde: "Eu não acredito nesses números, o cara morreu de uma gripe qualquer e colocam que morreu de coronavírus".

5 Em 28 de março de 2020, quando o Brasil registrou recorde de mortes pelo coronavírus (474 vidas perdidas em um único dia) e ultrapassou a China em número de óbitos (acima de 5000), o presidente, ao ser questionado sobre a gravidade do problema, respondeu com o habitual menosprezo: "E daí? Lamento. Quer que eu faça o quê? Eu sou Messias, mas não faço milagre”. Suas palavras escandalizaram o Brasil e o mundo pelo nível de frieza, desumanidade, falta de empatia e insensibilidade. Um dia depois, após voltar de um passeio frugal pela capital do país, Bolsonaro afirmou que, para se enfrentar o vírus, é necessário agir "como homem". "Essa é uma realidade, o vírus está aí. Vamos ter que enfrentá-lo, mas enfrentar como homem, porra. Não como um moleque. É a vida. Todos nós iremos morrer um dia." Sem esboçar qualquer estratégia sustentável de combate à pandemia, e inepto para liderar e conduzir a sociedade na travessia da crise, o ex-capitão trata a pandemia com menosprezo e, em um memorável pronunciamento à nação, compara a nova doença a uma "gripezinha".

6 O chefe do Executivo reiteradas vezes minimizou as mortes por Covid-19 alegando que morrer é o destino inexorável de todo mundo, em vez de reconhecer que o elevado índice de letalidade se deve ao combate tíbio à doença no Brasil. $\mathrm{O}$ descontrole que se viu da pandemia em alguns países é resultado direto da negligência de seus governantes, que como Bolsonaro fizeram vistas grossas e negaram a gravidade do problema. Desde o início da pandemia, o presidente tenta afastar de si a responsabilidade que lhe cabe como maior mandatário do país. Em 20 de abril de 2020, declarou: "não sou coveiro". "Aproximadamente $70 \%$ da população vai ser infectada. Não adianta querer correr disso. É uma verdade. Estão com medo da verdade?” declarou o presidente no mesmo dia. Segundo ele, "houve uma potencialização das consequências do vírus. [...] Levaram o pavor para o público, histeria. E não é verdade. Estamos vendo que não é verdade. Lamentamos as mortes, e é a vida. Vai morrer", afirmou, com palavras que chocaram o país e o mundo pelo nível de desumanidade e frieza. Naquele momento, o Brasil registrava a marca de 2575 mortes e 40.581 casos confirmados de pessoas contaminadas pelo novo coronavírus. A doença, que teve início com indivíduos de camadas sociais mais abastadas que se infectaram em viagem pela Europa e carregaram o vírus para o Brasil, chegava com força aos mais pobres, às periferias desassistidas, e começava a seguir sua trajetória de interiorização. Decorridos quatro meses desde o registro da primeira morte (12 de março de 2020), o país contabilizava 72.151 óbitos por Covid-19 e 1.866.176 brasileiros infectados, mantendo-se estacionado no mais longo platô de óbitos observado em todo o mundo. 
7 Gomes, M. E. (2020, Maio 24). Combate à desigualdade é bom apenas para o discurso, disse Guedes. Veja. Recuperado de https://veja.abril.com.br/blog/marcos-emilio-gomes/ combate-a-desigualdade-e-bom-apenas-para-o-discurso-disse-guedes /

8 Em 3 de junho de 2020, quando o país contabilizava mais de 30 mil mortos e exibia uma curva ascendente de contágio, alçando à posição vexatória de epicentro da pandemia na América Latina, o capitão voltou a se esquivar de qualquer responsabilidade e declarou que ninguém havia morrido na UTI por falta de respiradouro. Na última semana de junho, apenas em Natal (RN) estima-se que mais de 200 pessoas haviam perdido a vida enquanto aguardavam, sufocadas, por um leito de terapia intensiva.

\section{Referências}

Alexandre, V. \& Santos, M. A. (2019). Experiência conjugal de casal cis-trans: contribuições ao estudo da transconjugalidade. Psicologia: Ciência e Profissão, 39(n.spe 3), e228629, 1-13. https://doi.org/10.1590/1982-3703003228629

Associação Nacional de Travestis e Transexuais - ANTRA. (2020). Dossiê dos assassinatos e da violência contra pessoas trans brasileiras. Recuperado de https://antrabrasil.files.wordpress. com/2020/01/dossic3aa-dos-assassinatos-e-da-violc3aancia-contra-pessoas-trans-em-2019.pdf

Balzer, C. \& Hutta, J. S. (2012). Transrespect versus Transphobia Worldwide: Uma Revisão Comparativa da Situação dos Direitos Humanos de Pessoas com Variante de Gênero / Trans. Würzburg, GERM.: Flyerarlarm.

Baptista-Silva, G., Hamann, C., \& Pizzinato, A. (2017). Casamento no cárcere: agenciamentos identitários e conjugais em uma galeria LGBT. Paidéia (Ribeirão Preto), 27(1), 376-385. https://doi.org/10.1590/1982-432727s1201702

Bento, B. (2004). Da transexualidade oficial às transexualidades. In A. Piscitellli, M. F. Gregori, \& S. Carrara (Orgs.), Sexualidade e saberes: convenções e fronteiras (pp. 143-172). Rio de Janeiro: Garamond.

Butler, J. (2019). Vida precária: os poderes do luto e da violência (A. Lieber, trad.). Belo Horizonte: Autêntica. (Original publicado em 2004)

Butler, J. (2020). The force of non-violence: an ethico-political bind. New York: Verso.

Caravaca-Moreira, J. A. \& Padilha, M. I. (2018). Necropolítica trans: diálogos sobre dispositivos de poder, morte e invisibilização na contemporaneidade. Texto Contexto - Enfermagem, 27(2). e3770017. https://doi.org/10.1590/0104-07072018003770017

Conselho Regional de Psicologia São Paulo - CRP-SP. (2020). Enfrentamento da transfobia e os desafios para os tempos de isolamento social. Recuperado de https://www.youtube.com/ watch? $\mathrm{v}=$ DDJanDbmggs

Costa-Val, A. \& Guerra, A. (2019). Corpos trans: um ensaio sobre normas, singularidades e acontecimento político. Saúde e Sociedade, 28(1), 121-134. https://doi.org/10.1590/s0104$\underline{12902019170251}$ 
Deb, S. (2020). Living on the edge: Covid-19 adds to distress and discrimination of Indian transgender communities. Health and Human Rights Journal. Recuperado de https://www. hhrjournal.org/2020/03/living-on-the-edge-covid-19-adds-to-distress-and-discrimination-of-indian-transgender-communities/

Duarte, M. J. C. (2020). Vidas precárias e LGBTQIfobia no contexto da pandemia: a necropolítica das sexualidades dissidentes. Recuperado de https://www.apesjf.org.br/wp-content/uploads/ LGBT Convid 19 APES-1.pdf

Fernandes, L. \& Barbosa, R. (2016). A construção social dos corpos periféricos. Saúde e Sociedade, 25(1), 70-82. https://doi.org/10.1590/So104-12902016146173

Ferreira, L. \& Santos, S. (2020). Isolamento social limita acesso de população a tratamento transexualizador no SUS. Gênero e Número. Recuperado de http://www.generonumero.media/ isolamento-acesso-trans-saude/

Lasch, C. (1991). Refúgio num mundo sem coração: a família - santuário ou instituição sitiada? (Í. Tronca \& L. Szmrecsanyi, trads.). Rio de Janeiro: Paz e Terra.

Lira, A. N. \& Morais, N. A. (2020). Psychosocial adjustment profiles of gay and lesbian individuals involved in marital relations: a cluster-based analysis. Paidéia (Ribeirão Preto), 30, e3013. https://doi.org/10.1590/1982-4327e3013

Mbembe, A. (2018). Necropolítica: biopoder, soberania, estado de exceção, política da morte (R. Santini, Trad.). São Paulo: N-1.

ONU Mulheres Brasil. (2020). Mulheres lésbicas, bissexuais e transexuais contam os desafios da população LBT na pandemia da Covid-19. Recuperado de http://www.onumulheres.org.br/noticias/mulheres-lesbicas-bissexuais-e-transexuais-contam-os-desafios-da-populacao-lbt-na-pandemia-da-covid-19/

Oliveira, F. A. G., Carvalho, H. R. \& Jesus, J. G. (2020). LGBTI+ em tempos de pandemia da Covid-19. Diversitates Internacional Journal, 12(2), 61-96. http://diversitates.uff.br/index.

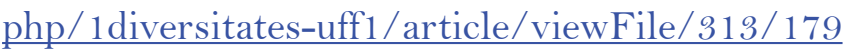

Oliveira, W. A., Oliveira-Cardoso, É. A., Silva, J. L. S., \& Santos, M. A. (2020). Impactos psicológicos e ocupacionais das sucessivas ondas recentes de pandemias em profissionais da saúde: revisão integrativa e lições aprendidas. Estudos de Psicologia (Campinas), 37, e200066. http://dx.doi.org/10.1590/1982-0275202037e200066

ONU Mulheres Brasil (2020). Mulheres lésbicas, bissexuais e transexuais contam os desafios da população LBT na pandemia da Covid-19. Recuperado de http://www.onumulheres.org. $\mathrm{br} /$ noticias/mulheres-lesbicas-bissexuais-e-transexuais-contam-os-desafios-da-populacao-lbt-na-pandemia-da-covid-19/

Outright Action International. (2020). Vulnerability amplified: the impact of the Covid-19 pandemic on LGBTIQ people. New York: OutRight Action International. https:/ / outrightinternational.org/sites/default/files/CovidsReportDesign_FINAL_LR O.pdf

Perez-Brumer, A. \& Silva-Santisteban, A. (2020). Covid-19 policies can perpetuate violence against transgender communities: insights from Peru. AIDS and Behavior, 1-3. Advance online publication. https://doi.org/10.1007/s10461-020-02889-Z

Santos, M. A., Souza, R. S., Lara, L. A., Risk, E. N., Oliveira, W., Alexandre, V., \& Oliveira-Cardoso, É. A. (2019). Transexualidade, ordem médica e política de saúde: controle normativo do processo transexualizador no Brasil. Estudos Interdisciplinares em Psicologia, 10(1), 3-19. http://doi.org/10.5433/2236-6407.2019v10n 1 p03 
Soares, M. Feijó, M. R., Valério, N. I., Siquieri, C. L. S. M., \& Pinto, M. J. C. (2011). $\mathrm{O}$ apoio da rede social a transexuais femininas. Paidéia (Ribeirão Preto), 21(48), 83-92. https://doi.org/10.1590/S0103-863X2011000100010

Spink, M. J. P. \& Medrado, B. (2000). Práticas discursivas e produção de sentidos: a perspectiva da Psicologia Social. In M. J. P. Spink (Org.), Práticas discursivas e produção de sentidos no cotidiano: Aproximações teóricas e metodológicas (pp. 17-40). São Paulo: Cortez.

Sexuality Policy Watch [SPW] (2020). A política sexual em tempos de pandemia: maio e junho de 2020. Recuperado de https://sxpolitics.org/ptbr/a-politica-sexual-em-tempos-de-pandemia-maio-e-junho-de-2020/10970

\section{MANOEL ANTÔNIO DOS SANTOS \\ https://orcid.org/0000-0001-8214-7767}

Professor Titular da Faculdade de Filosofia, Ciências e Letras de Ribeirão Preto da Universidade de São Paulo (FFCLRP-USP) e do Programa de PósGraduação em Psicologia. Doutorado em Psicologia Clínica pelo Instituto de Psicologia da Universidade de São Paulo (1996) e Livre Docência pela Faculdade de Filosofia, Ciências e Letras de Ribeirão Preto, Universidade de São Paulo (2011).

Endereço institucional: Universidade de São Paulo - Faculdade de Filosofia, Ciências e Letras de Ribeirão Preto. Departamento de Psicologia. Av. Bandeirantes, 3900, Monte Alegre. CEP 14040-901, Ribeirão Preto/ SP. E-mail: masantos@fffclrp.usp.br

\section{WANDERLEI ABADIO DE OLIVEIRA https://orcid.org/0000-0002-3146-8197}

Docente Permanente do Programa de Pós-Graduação Stricto Sensu em Psicologia da PUC-Campinas. Psicólogo, Doutor em Ciências (Doutorado Direto) pela Universidade de São Paulo (USP), em cotutela com a Scuola di Dottorato di Ricerca in Psicologia da Università Cattolica del Sacro Cuore (Milão-Itália). Realizou estágio de pós-doutorado no Departamento de Psicologia da Faculdade de Filosofia, Ciências e Letras de Ribeirão Preto (FFCLRP/USP), com bolsa de pós-doutorado no país da Coordenação de Aperfeiçoamento de Pessoal de Nível Superior (PNPD-CAPES, código de financiamento 001).

E-mail:wanderleio@hotmail.com

\section{ÉRIKA ARANTES DE OLIVEIRA-CARDOSO \\ https://orcid.org/0000-0001-7986-0158}

Professora Permanente do Programa de Pós-Graduação em Psicologia da Faculdade de Filosofia, Ciências e Letras de Ribeirão Preto (FFCLRP/ USP). Psicóloga, Doutora em Psicologia pela Universidade de São Paulo (2004). Psicóloga do Departamento de Psicologia e Educação da Faculdade de Filosofia, Ciências e Letras de Ribeirão Preto - FFCLRP-USP.

E-mail: erikaao@fffclrp.usp.br 


\begin{tabular}{|c|c|}
\hline Histórico & $\begin{array}{l}\text { Submissão: 01/07/2020 } \\
\text { Revisão: 27/07/2020 } \\
\text { Aceite: 31/07/2020 }\end{array}$ \\
\hline $\begin{array}{l}\text { Contribuição } \\
\text { dos autores }\end{array}$ & $\begin{array}{l}\text { Concepção: M.A.S. } \\
\text { Coleta de dados: M.A.S.; W.A.O.; E.A.O.C. } \\
\text { Análise de dados:M.A.S.; W.A.O.; E.A.O.C. } \\
\text { Elaboração do manuscrito: M.A.S.; W.A.O.; E.A.O.C. } \\
\text { Revisões críticas de conteúdo intelectual importante: } \\
\text { M.A.S.; W.A.O.; E.A.O.C. } \\
\text { Aprovação final do manuscrito: M.A.S. }\end{array}$ \\
\hline $\begin{array}{l}\text { Consentimento } \\
\text { de uso de imagem }\end{array}$ & Não se aplica. \\
\hline $\begin{array}{l}\text { Aprovação, ética } \\
\text { e consentimento }\end{array}$ & O estudo contou com aprovação ética. \\
\hline Financiamento & $\begin{array}{l}\text { Bolsa de Produtividade em Pesquisa do Conselho Nacional de } \\
\text { Desenvolvimento Científico e Tecnológico- } \mathrm{CNPq}, \mathrm{PQ}-1 \mathrm{~A} \text {, concedida ao } \\
\text { primeiro autor. }\end{array}$ \\
\hline
\end{tabular}

